\title{
IN DEFENCE OF ERROR THEORY
}

\section{Chris Daly and David Liggins}

\section{University of Manchester}

\section{$1 \quad$ Introduction}

To be an error theorist of a discourse is to claim that none of its sentences is true. For instance, error theorists of arithmetical discourse interpret ' $2+2=4$ ', 'There is an even prime', and many other sentences of the discourse as entailing the existence of numbers: they hold that these sentences are all untrue because numbers do not exist. Another example is error theory about moral discourse. On this view, moral sentences such as 'We morally ought to give money to charity' entail that there are objective values; but there are no such values, so such sentences are untrue.

The definition of error theory just given is a simplification, since the error theorist in fact claims that some sentences of the discourse are true. For instance, consider the sentences 'All numbers are prime' and 'There is no odd prime number', which are not plausibly interpreted as entailing the existence of numbers. The error theorist of arithmetical discourse claims that, since there are no numbers, such sentences are vacuously true. In the same way, the error theorist of moral discourse claims that 'It is not the case that we ought to give money to charity' is vacuously true, as is the negation of any sentence ascribing a moral obligation. Strictly speaking, to be an error theorist of a discourse is to claim that none of its sentences is non-vacuously true. For simplicity's sake, we will ignore this complication and focus on the sentences which error theorists claim are untrue. Note that as error theory, as we conceive it, is a claim about the truth-values of sentences, an error theory does not obviously involve imputing error to anyone (cf. Hurley 1989 p.278.)

Many contemporary philosophers rate error theories poorly. Error-theoretic accounts of a discourse are often completely ignored. ${ }^{1}$ When error theories are mentioned, they are commonly dismissed out of hand, as if it were well known that such positions are never the best ones available. Some other dismissals are slightly more detailed: they at least gesture at reasons to reject the error theory in question. For instance, it is hinted that considerations of charity, or of theoretical conservativeness, justify us in rejecting error theories. A small minority of philosophers offer more developed attacks. Our aim is to raise the standing of error theories. To do so, we will identify the

\footnotetext{
${ }^{1}$ Let us give two examples from recent textbooks of metaphysics. According to Jubien (1997, p.25), nominalists all agree that sentences like 'Seven is less than nine' are true: they undertake to explain how they can be true if there are no numbers. Loux (2002, pp.15-16) assumes that all philosophers debating the existence of somersaults will agree that sentences like 'George performed five somersaults between 3 p.m. and 4 p.m. on Thursday' are true: he says that their disagreement concerns what makes these sentences true. This example is meant to illustrate 'the nature of metaphysical disputes' (p.15.)
} 
arguments these philosophers invoke, and expose their deficiencies. In this way, we will show that error theories cannot be so quickly dismissed: they demand more serious consideration.

It will be useful to distinguish different types of error theory. Some error theorists claim that we do not believe the propositions expressed by the sentences of the discourse: instead, we accept them, where accepting a proposition involves no commitment to its truth. Such error theorists are hermeneutic fictionalists. By contrast, revolutionary fictionalists accept that many of us do believe these propositions, including many untrue ones; they advise us to stop believing these propositions, and to merely accept them instead. (So revolutionary fictionalists hope that hermeneutic fictionalism will come true.) Another option for error theorists who accept that many of us believe many of these propositions is to advise us to abandon the discourse altogether, just as we have abandoned phlogiston-talk. We call these error theorists eliminativists. As we will see, many objections to error theory focus on the claim that many of our beliefs are untrue: hermeneutic fictionalism neatly side-steps all such assaults by rejecting this claim. But hermeneutic fictionalism faces serious objections. In many cases, it conflicts with the introspective data: it seems to us that we do believe the propositions which hermeneutic fictionalists claim we merely accept (see Eklund 2007.) And it has been argued that the most popular form of hermeneutic fictionalism - which claims that we pretend that the propositions in question - is refuted by the existence of speakers who are unable to pretend but who nevertheless participate in the discourse successfully (see Stanley 2001.) These objections to hermeneutic fictionalism await proper assessment. Meanwhile, error theorists would be well advised not to dismiss revolutionary fictionalist or eliminativist positions.

To make our case, we begin by pointing out a general constraint which objections to error theories must satisfy. Then we rebut Paul Horwich's allegation that error theories cannot be respectably motivated (section 3.) Another possible source of resistance to error theories is the idea that they are incompatible with reflective equilibrium: this challenge is met in section 4 . The next four sections reply to objections to error theories stemming from concern for particular theoretical virtues: honesty, charity, ideological economy, and conservatism. Here we pay particular attention to the work of David Lewis, Crispin Wright, Mark Johnston, and Peter van Inwagen. To close, we discuss whether Moorean respect for common sense, or naturalist respect for science, present us with general reasons to reject error theories, concluding that they do not (sections 9, 10.) In this way, we will establish that error theories demand much more serious treatment that they are typically afforded. ${ }^{2}$

\footnotetext{
${ }^{2}$ Certain forms of expressivism count as error theories by our definition. We are happy to contribute to the defence of these expressivist theories.
} 


\section{How not to object to error theories}

The following constraint holds on viable objections to error theory. Philosophers need to take care that their chosen objection to a given error theory does not prove too much by yielding a more general objection that applies to any error theory. Error theories about certain discourses are compelling: we should be error theorists about, for example, astrology, palmistry and numerology. This places an important constraint on objections to error theory. An objection to a philosophically controversial error theory should not provide an objection to a philosophically uncontroversial error theory.

To illustrate this point, consider the following two objections to Mackie's moral error theory. First, an objection from Putnam (Putnam 1983, p.177, his italics):

. . Mackie (1977) argues that values are 'ontologically queer', i.e., not part of the furniture of the world. What is so strange about all this is that Kant already taught us that the whole idea of comparing our conceptual system with a world of things-in-themselves . . . to see if the conceptual system 'copies' the unconceptualized reality is incoherent. The idea of comparing our conceptual system with a conceptual system which is 'built in' to the world, a unique 'right way' in which the world can be seen, is also incoherent.

We do not pretend to understand fully all of Putnam's above remarks. But we understand this much: there is nothing specifically about values in the lessons that Putnam draws from Kant. What Putnam has come up with is an all-purpose defense of the existence of $K$ s, for any kind of entity $K$. So if Putnam's remarks form an objection to the view that values do not exist, those same remarks form an objection to any view about what does not exist. Putnam's argument thereby proves too much. Moreover, since we can have warranted beliefs that certain kinds of thing do not exist - perpetual motion machines, Loch Ness monsters, or Iraqi weapons of mass destruction - without contravening Kant's metaphysical doctrines, it is not clear why Mackie's argument should contravene them. None of these arguments need attempt to compare a 'conceptual system' with 'unconceptualised reality'. They simply cite evidence against the existence of instances of the kind of thing in question, or they cite the absence of evidence for the existence of such instances.

Our second example runs: Disagreement makes sense only against a background of widespread agreement; therefore, moral disagreement makes sense only against a background of moral agreement. So other people's moral beliefs are largely the same as ours, and so true by our lights. 'Thus, as we've seen, only against a background of veridicality and agreement do the possibilities of error and disagreement [in value judgements] make sense' (Hurley (1989) p.93. She is referring back to chapters 2 and 3 of her book.) This objection also proves too much. The objections can be run, mutatis mutandis, 
to conclude that (say) most superstitious beliefs are true. The objections have a common flaw. They infer invalidly from what is (supposedly) the case with respect to people's total set of beliefs to what is the case with respect to a proper subset of those beliefs. Even if most of our beliefs are true, it does not follow that most of our moral beliefs are true. Even if we disagree about some matters of fact only if we agree about most matters of fact, it does not follow that we disagree about some matters of morality only if we agree about most matters of morality.

\section{Can error theories be motivated?}

Error theorists usually argue for their position by trying to show that the sentences of the discourse in question all entail an untruth - typically an untrue existential claim. Thus error theorists of morality attempt to show that moral sentences entail that there are objective values, and that no such values exist; error theorists of arithmetical discourse attempt to show that arithmetical sentences entail that there are numbers, and that there are no numbers; and so on. Call these metaphysical arguments for error theory.

Paul Horwich claims that, if we pre-theoretically believe that some of the sentences of a discourse are non-trivially true, then no metaphysical argument for an error theory of it can succeed. His argument is therefore aimed at eliminativist and revolutionary fictionalist forms of error theory; it is no threat to hermeneutic fictionalism. Horwich (1998, p.88) claims that, although there are good scientific arguments against the existence of certain entities, philosophical reflection can supply no good arguments for such conclusions. Addressing metaphysical arguments for error theory, he writes:

There are three types of response to any such argument: (a) we may regard it as fallacious, and proceed to explain how this is so; (b) we may find it persuasive, accept that $K$ s don't exist, and conclude that a certain body of what we used to believe is mistaken; or (c) ... we might abandon the account of logical forms that involves commitment to $K$ s and replace it with one that doesn't.

Of these alternatives it seems clear that option (a) is always best; for the arguments that it asks us to reject are extremely weak in the first place. Often they involve barefaced overgeneralization of the following sort. First, material objects are taken to be paradigm examples of what exists; secondly, certain prominent properties of such objects are identified; thirdly, it is inferred that only entities with these properties could exist; fourthly, it is noticed that $K$ s would not have them; and finally, the conclusion is drawn that $K$ s cannot exist. Evidently no great conceptual strain is involved in rejecting such arguments, which beg the whole question in their first premise. So option (a) is quite acceptable. The other alternatives, however, exhibit some highly undesirable features. Option (b) implies that we must start denying certain things that we presently regard as certainly true. Option (c) involves the idea that the correct logical 
forms are not those that provide a perfectly adequate account of inferential practice. We are to reject a certain way of articulating our beliefs solely because it has consequences that are irrationally regarded as unwelcome .... (Horwich 1998, p.89; see also Horwich 2006a, pp. 198-2000 and Horwich 2006b, p. 12)

Later (p.90), Horwich adds an example of the sort of over-generalization he has in mind: arguing against the existence of non-causal entities such as numbers and propositions on the ground that since truths about physical objects are known by causal contact, all knowledge must involve such contact.

It is not clear whether Horwich is trying to argue that no metaphysical argument for error theory could ever succeed, or just that none of the metaphysical arguments that have been actually been offered actually does succeed. We'll read him as aiming to for the latter, weaker, conclusion, and argue that he fails to establish it; if we are right, we will also show that he fails to establish the former conclusion.

In the second paragraph of the quotation, he describes a certain form of argument error theorists might use, and claims that it relies on question-begging over-generalization. He is quite right: any such argument would indeed be question-begging. But Horwich has given us no reason to think that every argument against the existence of $K \mathrm{~s}$ takes this form. Even if many metaphysical arguments for error theory involve question-begging over-generalization, that does not show that they all do. Ironically, then, Horwich is himself guilty of over-generalization.

Moreover, error theorists have offered many arguments against the existence of entities of certain types which do not take the form which Horwich describes. Let us give some examples.

Field (1989, pp.230-232) argues for an error theory of mathematical discourse by arguing that, if there were mathematical entities, it would be impossible to explain why mathematicians' beliefs about them are typically true. Field's argument is a refurbished version of an argument put forward by Paul Benacerraf (1973); but whereas Benacerraf assumes that causal contact is necessary for knowledge, Field assume no such constraint; rather, he assumes that any theory which prevents us from explaining mathematicians' reliability is thereby rendered highly undesirable (see Liggins 2006.)

Mackie (1977, chapter 1) argues for an error theory of moral discourse on the ground that, if any moral sentence were true, then there would be objective values. Mackie offers several arguments against the existence of such things. One of them runs as follows: 'If there were objective values, then they would be entities or qualities or relations of a very strange sort, utterly different from everything else in the universe' (p.38.) Perhaps this argument involves the sort of over-generalization Horwich highlights. But Mackie's other arguments do not. For instance, Mackie argues that if there were objective values, it would be difficult to explain how we know about them. His objection is based on the idea that none of our familiar faculties could deliver knowledge of objective values. Mackie grants that 
some knowledge may be acquired by conceptual analysis or introspection, but he doubts that moral knowledge can be picked up this way. These are not ways of knowing about the properties of material things, so Mackie is not taking knowledge of material things as the template for all knowledge. Another argument of Mackie's concerns disagreement: he contends that the best explanation of societies' differing moral codes makes no reference to our possessing knowledge of objective values. This reasoning involves no general claim about what sorts of things exist, so it does not conform to the pattern of argument that Horwich criticizes.

Other error theorists offer arguments resembling this argument of Mackie's. Error theorists about colour discourse, for instance, claim that we should disbelieve in colours because they serve no explanatory purpose (see Brock and Mares 2007, p.99); and Russell (1912) argues that causal discourse is false by citing the absence of such talk from science.

Philosophers have also argued for error theories on logical grounds. Some well-known arguments for the falsity of monotheistic discourse contend that it is logically impossible for anything to be omnipotent; there are parallel arguments concerning other properties ascribed to the deity, such as omniscience. Similarly, some error theorists of talk about fictional characters argue for their view in the following way: if sentences like 'Marlow is Conrad's most famous character' were true, then there would be indeterminate identities; but there are not (Evans 1982), so such sentences are untrue (see Everett 2005, pp.628-633.) It is clear that Evans's argument against indeterminate identity is purely logical.

We could go on; but the moral is clear. Horwich has seriously under-estimated the range of arguments that could be deployed in support of error theories. There are many metaphysical arguments for error theory which do not involve over-generalizing from the properties of material objects: Horwich has not refuted any of these arguments. It follows that he has failed to show that error theorists are always (as he puts it) 'irrational' to deny the existence of mathematical objects, objective values, colours, causes, fictional characters, or God.

Discussing option (b), Horwich claims that it is 'highly undesirable' to deny 'things that we presently regard as certainly true'. It's not clear that we can regard any of our beliefs as certain, strictly speaking; so it seems that Horwich is best interpreted as claiming that it is highly undesirable to deny things we are confident are the case, or that we regard as highly likely to be true. But Horwich provides us with no argument to show that this is at all undesirable. If good scientific arguments can overturn our beliefs, why can't good philosophical arguments do the same?

Perhaps Horwich will say that certain of our beliefs are epistemically privileged, so that scientific or philosophical arguments cannot readily displace them. In particular, he might take our most confident beliefs to have that status. It is to this line of thought that we now turn. 


\section{$4 \quad$ Reflective equilibrium}

Philosophers might be hostile to error theories because they believe that that reflective equilibrium is the correct method for conducting philosophical enquiries, and that it could never lead to an error theory. We will argue that this line of thought is at least half wrong; whilst reflective equilibrium may well be the right way to philosophize, there is no reason why it cannot be used to establish an error theory.

The method is familiar one. We start off with a large number of beliefs, some of them pre-philosophical, others more theoretical, and we try to find a theory which (i) preserves as many of these beliefs as possible; and (ii) is theoretically virtuous in other ways: consistent, simple, powerful in explanation, and so on. If our beliefs are inconsistent, then there is clearly no way of reconciling these two demands; and even if they are consistent, it is still highly unlikely that both demands can be met. So we strive to find the best balance between (i) and (ii): a reflective equilibrium. It is plausible that this is the only rational method of inquiry in philosophy; any other method will involve ignoring relevant considerations or some other failure of rationality (see DePaul 1998.)

It is easy to see why philosophers might think that this method could not deliver an error theory. The philosopher using reflective equilibrium is trying, among other things, to preserve as many of our pre-philosophical judgements as possible: but error theorists of a discourse, unless they are hermeneutic fictionalists, maintain that very many of our pre-philosophical judgements are untrue. How, then, could reflective equilibrium lead one to adopt an error theory?

The answer is that the theory which offers the best balance between (i) and (ii) may satisfy (i) very imperfectly. Suppose, for instance, that incorporating many of our pre-theoretical judgements into a theory would drastically reduce its economy or explanatory power or both. Then the theory which offers reflective equilibrium may satisfy (ii) very well but (i) hardly at all. Preserving our intuitive judgments is one goal of theory-construction, but there is no guarantee that that the most virtuous theory will have this particular virtue: a theory which sacrifices many intuitive judgements may be the best one overall. For instance, perhaps any theory which preserves our pre-theoretical beliefs about mathematics will be unable to explain how many of our mathematical beliefs come to be true, and thus lack the power to explain a central phenomenon; if so, then the best account of mathematics may well involve the rejection of these pre-theoretical beliefs. In short, we agree with Lewis (1986, p.134): 'Common sense has no absolute authority in philosophy'.

We have presented the issue as though there is a unique theory that reaches reflective equilibrium. This is a simplifying assumption. More realistically, there will be more than one theory that reaches reflective equilibrium (Lewis 1983, pp.x-xi.) If anything, this strengthens the error theorist's hand. For if more than one theory can reach reflective equilibrium, then it seems more likely that an 
error theory can be found among such theories. At any rate, it seems more pressing on the opponent of error theories to give a reason for saying why an error theory will not be among the theories that achieve reflective equilibrium.

The opponent of error theories might reply by arguing that no error theory can satisfy (ii) very well: we should avoid error theories, not simply because they clash with common sense, but because they contravene some important theoretical norm thereby. In the next four sections, we discuss four arguments of this sort, citing the norms of honesty, charity, ideological economy, and conservatism. We will show that these arguments all fail.

\section{Honesty}

Lewis (1986, p.135) offers a 'simple maxim of honesty: never put forward a ... theory that you yourself cannot believe in your least philosophical and most commonsensical moments'. At first sight, this appears to challenge many error theories. For instance, the claim that there are no tables is often branded 'unbelievable' - and if that is literally the case, Lewis's maxim rules out any theory which incorporates it.

On behalf of error theorists, we offer a two-fold reply. First of all, we should not under-estimate what we can bring ourselves to believe. Several philosophers claim to hold radical beliefs, such as the belief that there are no tables: unless countervailing evidence can be cited, we should take them at their word. That some people actually believe error-theoretic claims is excellent evidence of their believability. Secondly, Lewis's maxim is implausible. That is because it is attractive to think of philosophy, and other intellectual inquiries, as normative: in conducting them, we try to work out what we ought to believe about the subject-matter in question. If that is right, them we may well conclude that that we ought to form a certain belief, but find ourselves unable to do so. It is unclear why our capacities for forming beliefs should constrain our thinking about what we ought to believe, any more than our moral weakness should constrain our ethical thinking. There is nothing wrong with putting forward a moral code that one sometimes contravenes.

\section{Charity}

It is sometimes thought that error theory conflicts with the principle of charity. Frank Jackson, for example, advises that 'we work on the general presumption that the folk are not badly confused', and takes this to be a reason against accepting error theory about colour discourse (Jackson 1998, p.103.) This general policy raises three questions:

Which formulation of the principle of charity is in question? 
How plausible is that formulation?

Does the principle as formulated conflict with error theory?

As a first approximation, the principle of charity says that, in interpreting people, we should assume that their beliefs are largely true. The principle admits of different formulations. Arguably, the logically stronger the formulation, the less plausible the principle formulated. A strong formulation tells us to interpret people as having untrue beliefs, or as being irrational, only given overwhelming evidence. Thus Davidson (1973-4, p.19) writes that:

Since charity is not an option, but a condition of having a workable theory [of radical interpretation], it is meaningless to suggest that we might fall into massive error by endorsing it. Until we have successfully established a systematic correlation of sentences held true with sentences held true, there are no mistakes to make. Charity is forced on us; - whether we like it or not, if we want to understand others, we must count them right in most matters.

But, as Thagard and Nisbet persuasively argue, such a formulation is 'likely to block understanding of human behavior and impede progress toward improving it' (Thagard and Nisbett 1983, pp.250-1. For further discussion of Davidson's view, see McGinn 1977 pp.521-30, Vahid 2001, Lepore and Ludwig 2005, chapter 13, and Williamson 2007, pp.260-70.) A weaker, and more plausible, formulation tells us not to grant any special favour to the hypotheses that people have untrue beliefs or that they are irrational. Interpreters should not judge someone to have untrue beliefs unless they have a justified account of why that person has those beliefs. Likewise, interpreters should not judge an individual to have irrational beliefs unless they have a justified account of why that person has those beliefs. For example, the account might say that the individual has those beliefs, despite their being irrational, because of their utility. Or the individual may have acquired those beliefs through membership of a culture that originally formed those beliefs on a much more slender evidential base than we now have. It is perhaps this last consideration that prompted Russell to regard common sense as the metaphysics of the Stone Age. (Russell wrote, for example, that 'the thing [i.e. physical object] was invented by the prehistoric metaphysicians to whom common sense is due' (Russell 1914 p.148.)

Jackson's above quoted claim that 'we work on the general presumption that the folk are not badly confused' is ambiguous. One's beliefs may be badly confused by being largely untrue or by being irrational (more fully: by being synchronically probabilistically incoherent.) Several philosophers have argued that charity requires that we maximise the attribution of rationality to a person's beliefs, not that we maximise the attribution of truth to those beliefs (see Grandy 1973 p.440f, Lewis 1983a, pp.112-3, 
and Wiggins 1980, pp.198-200.) Unless it is a form of hermeneutic fictionalism, an error theory attributes untrue beliefs to people, but it need not impugn the rationality of those beliefs. (Need not, but may. One way of having a untrue belief is to have an incoherent set of beliefs.) Attributing untrue beliefs to a person is not uncharitable provided that an explanation is given of why they have the beliefs attributed to them, given their evidence. John Devlin thinks that an error theory faces a challenge here:

The attribution of systematic error must play an essential role in the best explanation of the constitutive features of the discourse. Otherwise an error theory should be abandoned in favor of a second-order theory which meets the same desiderata on explanation without the attribution of widespread error. But in the absence of a compelling explanation for the intelligibility and scope of our supposed error, it seems prima facie implausible to suppose we are systematically mistaken. (Devlin 2003, pp.54-5)

We agree that any error theory faces this challenge, but wish to remove a potentially misleading impression that the challenge may give. It potentially misleads because it may suggest that error theory faces a special challenge and so that it should never be our theory of first choice. But note that an equal challenge faces a realist theory - a theory that takes the sentences of the target discourse to be largely true. The attribution of widespread truth to those sentences must itself play an essential role in the best explanation of the constitutive features of that discourse. Otherwise a realist theory should be abandoned in favour of a second-order theory which meets the same desiderata on explanation without the attribution of widespread truth. (Such a theory might be an error theory or an agnostic theory or an expressivist theory.) But in the absence of a compelling explanation of why we have so many true beliefs, it seems prima facie implausible to suppose that those beliefs are largely true. Our point is that if the extent of our errors ought to have a compelling explanation, then so too should the extent of our knowledge (and of our ignorance as well.)

As a case study of the use of the principle of charity against error theory, we will consider some recent work by Crispin Wright. Wright frames his discussion of error theory in terms of which notion of truth should be applied to the statements of a given discourse. Wright champions a notion of truth which he calls 'superassertibility' (see Wright 1992, p.85f.) A statement $S$ is superassertible iff $S$ is assertible and it remains assertible no matter how much further information is gathered. In Wright's words:

A statement is superassertible if and only if it is, or can be, warranted and some warrant for it would survive arbitrarily close scrutiny of its pedigree and arbitrarily extensive increments to or other forms of improvement of our information (Wright 1992, p.48.) 
Wright argues that we should accept superassertibility accounts of (for example) morality and mathematics rather then error theoretic ones. His argument explicitly appeals to considerations of charitable interpretation. According to Wright (1994, p.172), error theorists are committed to:

a certain kind of account of the meaning of the statements of a contested discourse which the initial presumption should be against, once we see that a conception of truth is to hand which will avoid that charge of massive error. For charitable interpretation dictates that we should avoid that charge if we possibly can, that is, unless best sense is made of the discourse by an account of its content which sustains a gap between truth and superassertibility.

Two claims in the above passage should be distinguished. First, Wright places a certain requirement on error theory; namely, that it makes best sense of the meanings of the target discourse's statements. Second, Wright claims that there is an 'initial presumption' against error theory. As Wright elsewhere rhetorically asks (1992, p.10 (his italics)):

... why insist on construing truth for moral discourse in terms which motivate a charge of global error, rather than explicate it in terms of the satisfaction of the putative subsidiary norm[?]

Wright's requirement amounts to this: accept error theory only if it provides the best account of the meanings of the discourse's statements. This requirement is unexceptionable. It is a special case of the following general methodological requirement: given a choice between competing theories about any subject matter, we should choose only whichever theory is the best. What is not unexceptionable is Wright's second claim. His claim that there is an 'initial presumption' against error theory is the claim that error theory does not meet the requirement in question. The single reason given in the passage for that claim is that 'a conception of truth is to hand which will avoid that charge of massive error'. The conception of truth in question is the superassertibility conception. Wright's strategy is then to argue that while no ethical or mathematical sentences may be (non-vacuously) true on the conception of truth used by error theory, at least some of those sentences are true on the conception of truth used by the superassertibility account.

But this opposition between error theory and the superassertibility account is spurious. Any argument of the error theorist's to the effect that a sentence $S$ is not true on the conception of truth that the error theorist works with, will carry over as an argument to the effect that $S$ is also not true on the superassertibility conception of truth. For example, suppose $S$ is the sentence 'there are objective moral 
values'. The moral error theorist may argue that $S$ is not true because such values would be unlike anything else that exists. (See Mackie's argument from 'metaphysical queerness': Mackie 1977, p.38.) Whether Mackie's argument is a good argument is not the issue here. If it is a good argument, it is an equally good argument on the superassertibility conception of truth. Recall that, on that conception, a sentence is superasserible iff it is assertible and would remain assertible whatever further information comes in. According to Mackie's argument, the information that objective moral values would be unlike anything else that exists is information that tells against the assertibility of $S$. Mackie's argument is thereby also an argument against the superassertibility of $S$.

Wright construes assertibility (and superassertibility) in terms of assertibility (superassertibility) by a discourse's 'actual standards' (see Wright 1992, pp.86,87.) This does not, however, affect the above criticism. According to the moral error theorist, the standards of moral discourse include the standard: assert a moral sentence only if there are objective moral values. Given the information that there are no objective moral values, the standard enjoins us not to assert any moral sentence. (See also Jackson 1994, pp.167-8.)

Suppose we waive the preceding objection, and grant that Wright has shown is that there is an alternative to error theory, namely: superassertibility theory. Even so, Wright needs to do more. He needs to show that error theory is not the best theory. That is, he needs to show that superassertibility theory is not merely a rival to error theory, but is a better theory. The only reason that Wright offers is an appeal to charity, and we have rebutted that consideration earlier in this section. Moreover, it would be circular to argue that the superassertibility theory is a better theory because it does not impute systematic untruth to the sentences of the target discourse. What needed to be shown at the outset was that, by imputing systematic untruth to those sentences, error theory was thereby a bad theory. ${ }^{3}$

\section{$7 \quad$ Ideological economy}

In a series of papers, Mark Johnston has sought to undercut error theory in a fashion similar to Wright's attempt (Johnston 1992a, 1992b, 1993.) Both authors are reluctant to interpret the folk as making philosophically controversial assumptions. Johnston's strategy is as follows. Human beings have various practices. We have moral practices of classifying acts as morally right or wrong. We have practices of classifying events as past, present or future. We have practices of identifying and re-identifying persons. And so on. An error theory of such a practice claims that the practice involves certain untrue metaphysical assumptions. The view that Johnston champions ('Minimalism', as he calls it) makes three key claims. First, although practitioners may associate certain 'metaphysical pictures'

\footnotetext{
${ }^{3}$ Alex Miller (2002) has shown that, in the case of ethics at least, Wright's response to error theory suffers from a further weakness.
} 
(Johnston's phrase) with their practices, 'these practices are typically not dependent on the truth of the pictures' (Johnston 1992a, p.590.) Second, there are philosophical advantages in not taking the practices to depend on such metaphysical pictures: "we can do better in holding out against various sorts of skepticism and unwarranted revision when we correctly represent ordinary practice as having given no crucial hostages to metaphysical fortune' (Johnston 1992a, p.590.) Third, what justifies the practices are non-metaphysical considerations: 'practices that endure and spread are typically justified in nonmetaphysical [sic] terms' (Johnston 1992a, p.590.) As part of his campaign to conserve our traditional ways of life, Johnston defends minimalism about free will (1992a, pp.591-2), colour (1992b), and personal identity (1992a.)

Johnston regards error theories as ideologically bloated: they involve metaphysical concepts which our theories are better off without. By contrast, minimalism is 'the view that metaphysical pictures of the justificatory undergirdings of our practices do not represent the crucial conditions of justification of our practices' (Johnston 1992a, p.590.) He allies his project with Paul Horwich's minimalism about truth, which he takes to be claming that 'our ordinary concept of truth is free of any substantive metaphysics of correspondence' (Johnston 1992a, p.590, footnote 3.) Given the nature of this alliance, Johnston's minimalist project is evidently driven by concern for ideological economy.

Take Johnston's three claims in turn. The first is that our practices are not dependent on the truth of metaphysical pictures that are often associated with them. As Johnston puts it:

... the metaphysical pictures associated with [ordinary] concepts do not represent central beliefs of the users of those concepts which guide the users in applying the concepts. [Minimalism] has it that the metaphysical pictures are philosophical epiphenomena. Metaphysical pictures, although they emerge from the experience of ordinary concept users, do not guide ordinary practitioners in their everyday applications of the concepts and so do not represent the sort of central beliefs whose falsity would deprive the concepts of everyday application. (Johnston 1993, p.110)

The claim that certain practices are associated with metaphysical pictures, and that these pictures may distort our pre-reflective understanding of these practices, is familiar from the work of the later Wittgenstein. Wittgenstein takes Platonism in mathematics to be a metaphysical picture of mind-independent abstract objects that is grafted onto our smoothly functioning mathematical practice, despite the fact that the picture neither justifies the practice nor is mandated by it. Platonistic talk is an ill-advised rhetorical flourish (Dummett 1978, Tait 1986.) 
We think that what metaphysical assumptions our practices make have to be carefully established on a case-by-case basis. Empty rhetorical flourishes may not be the monopoly of one side. Contentious metaphysical assumptions that are essential to a certain practice can mistakenly be written off as an idle metaphysical picture imposed on the practice. The hard question is how to tell what is genuinely assumed by a practice from what is being read into it. Consider our practice of identifying and reidentifying physical objects. Locke took this practice to involve assuming the existence of a plurality of mind-independent material objects. We find it doubtful that the best reply to Berkeley's subsequent sceptical attack is to turn Minimalist and expose the Lockean view as a metaphysical picture foisted on a practice that is in perfectly good order as it stands. It seems much more plausible that the Lockean view correctly captures a contentious metaphysical assumption made by our ordinary practice and that there is no shirking the task of addressing Berkeley's criticisms head on.

Minimalism's second key claim is that 'we can do better in holding out against various sorts of skepticism and unwarranted revision when we correctly represent ordinary practice as having given no crucial hostages to metaphysical fortune'. Our practice of trafficking in physical objects, and the integral Lockean view of that practice, provides a counter-example to this unqualified methodological suggestion. Furthermore, the suggestion simply comes down to the claim that we should avoid being error theorists if there is an alternative. But why should a premium be set on avoiding error theory? The Minimalist owes an argument here. Note too the insidious wording in the quoted claim. To describe the revision as 'unwarranted', and the representation of the practice as non-metaphysical as a 'correct' representation, beg the question against the error theorist. What is at issue is whether a non-metaphysical representation is correct, and whether any revision in our practice is warranted.

Minimalism's third key claim is that what justifies our practices are non-metaphysical considerations. Two questions arise: What non-metaphysical factors provide the justification? What kind of justification is in question here? Minimalism's third claim is best understood by considering Johnston's treatment of personal identity. One might think that our practice of identifying and re-identifying persons is justified by posting Cartesian egos. But there are no Cartesian egos. What, then, justifies the practice? Johnston answers:

Ordinary self-referential concerns are natural and intelligible, and so far we have found no good critical case against them. This is as good a justification as we get for any of our basic attitudes and practices. (Johnston 1992a, p.618)

But if this answer suffices to explain what kinds of factor provide the justification, there remains the question of what kind of justification is being given. Johnston does not explicitly answer this question. It 
is unclear whether he is concerned with epistemic justification. At any rate, his comments leave this open. This provides a gap for the error theorist to exploit. Feigl distinguished between two kinds of justification: validation and vindication (Feigl 1950.) To validate a proposition is to provide epistemic reason to think that it is true; to validate a rule is to provide epistemic reason to think that it is valid. To vindicate a proposition or rule is to provide an instrumental or pragmatic justification for it. It is to show that accepting it is the best means of securing a desired end. An error theorist about personal identity (such as Parfit (1984)) can treat the factors that Johnston cites not as giving a validation of our beliefs about personal identity, but as providing a vindication of them. Our basic attitudes and practices about persons have great practical value; they meet certain of our 'ordinary self-referential concerns'. The error theorist can then co-opt the third component of Minimalism. A certain practice may make untrue metaphysical assumptions. But the practice may have sufficient utility for it to be retained without being reformed. We continue with the practice despite disbelieving its metaphysical assumptions. We are 'revolutionary fictionalists' about the practice. This story should be no news. It has long been many people's reflective attitude to talk of sunrises and sunsets (Boghossian and Velleman 1989, pp.100-1.) So, if anything, this species of fictionalism is a more familiar and quotidian option than Johnston's Minimalism.

To conclude: Johnston describes Minimalism as 'the position which a Revisionary Protagorean [i.e. an error theorist] must first overcome' (Johnston 1993, p.111.) We take this to mean that Johnston regards Minimalism as the default position in the debate between realism about Ks and its various opposing views. But, first, Johnston provides no non-question-begging case against error theories that abandon or reform practices. And, second, error theories that preserve practices can exploit Johnston's own policy of vindicating those practices. We have not found that Minimalism enjoys any eminence over error theory.

\section{$8 \quad$ Conservatism}

It might be thought that error theories conflict with the principle of epistemic conservatism (hereafter 'conservatism' for short.) It is difficult to identify a single representative version of this principle. We will take conservatism to say that a person is to some degree justified in retaining a given belief just because that person has that belief. According to conservatism, someone can correctly say that at least part of their reason for continuing to believe that $p$ is that they already believe that $p$. An error theory which says it is untrue that $p$ will have reasons for what it says. Those reasons will also be reasons for its saying that that anyone's belief that $p$ is (on balance) unjustified. Error theory and conservatism thereby apparently conflict. 
There are two mutually exclusive responses open to the error theorist. One response is concessive because it accepts conservatism; the other response is hard line because it rejects conservatism. Although the concessive response accepts conservatism, it takes any justification offered by conservatism to be defeasible. Conservatism may provide justification for a proposition, but other factors might together provide stronger reason against it. This view is independently plausible: Copernican theory and observation provided sufficient reason to revise the long-held belief that the Sun orbits the Earth. Moreover, taking conservatism to offer defeasible justification is not to take it to be peculiar. Many kinds of justification (perception, memory, inductive inference, ... .) are also defeasible. So conservatism is in good company.

The hard line response rejects conservatism. The response has two elements. First, it can be argued that conservatism itself lacks epistemic justification (cf. Christensen 1994 and Vahid 2004.) Second, there is reason against conservatism. Consider the following example of the opinionated coin flipper (Christensen 1994, p.74.) This individual flips (what he knows to be) a fair coin and, for no reason whatever, forms the belief that it has landed tails. The fact that he has formed this belief provides no reason for him to maintain his belief that the coin landed tails. The believer is merely dogmatic. Yet conservatism says that the coin flipper's belief is justified. So conservatism is false.

One reason for appealing to conservatism is to account for the phenomenon of 'lost justification' (Harman (1986.)) This is the phenomenon that people do not usually keep track of the justification relations among their beliefs. Harman takes this phenomenon to be a consequence of the fact that one should change one's beliefs only if one has a reason to do so. But the phenomenon can be equally well accounted for without invoking conservatism. The phenomenon is simply a consequence of the fact that one may be in the position of having a justified belief that $p$ (because one's belief that $p$ has some original source of justification, and the justification has not been undermined by any of one's beliefs at any subsequent time), although one is not in a position to show that one's belief that $p$ is justified (because one's justification for that belief is 'lost') (Vahid (2004) p.113.)

Peter van Inwagen suggests another motivation for conservatism: rejecting conservatism collapses into scepticism. He writes:

[A]ny philosopher who denies what practically everyone believes is, so far as I can see, adopting a position according to which the human capacity for knowing the truth about things is radically defective. And why should he think that his own capacities are the exception to the rule? (van Inwagen 1990, p.103) 
This passage points out a danger for the error theorist who claims that, before philosophical reflection, we believe many of the sentences of the discourse in question. Such a philosopher must say that many of our pre-theoretical beliefs are untrue. But that appears to threaten our capacity to find out the truth. For instance, perhaps the error theorist of arithmetic, who claims that we are all wrong about whether ' $2+2=4$ ' is true, will have to say that humans are just no good at knowing at all. If so, that would cast doubt on the error theorists' own claims to knowledge.

It is worth noting that van Inwagen's challenge does not touch hermeneutic fictionalist error theory. Hermeneutic fictionalists about arithmetic, for instance, could not claim that our arithmetical beliefs are untrue, because they claim we have no such beliefs. The same point obtains more generally: hermeneutic fictionalists about F-discourse do not attribute to us untrue beliefs about Fs.

But what about error theorists who do ascribe such beliefs to us? We believe that they can defend themselves from van Inwagen's argument. To see how, note that error theorists of arithmetic think that ' $2+2=4$ ' is untrue because it entails the existence of numbers, and there are no such things; in other words, it owes its falsity to its ontological implications. In contrast, consider the pre-theoretical belief 'All lions are animals'. This conditional belief does not imply any ontological doctrine, so then there can be no motivation to declare the sentence untrue on ontological grounds. It follows that there is no argument from error theory about mathematics to universal ignorance. Van Inwagen's argument would only have bite if it could be shown that all our beliefs carry controversial ontological implications; but it is widely agreed that our conditional beliefs do not. Error theories do not imply that the human capacity for knowing the truth about things is radically defective; rather, they imply that the human capacity for knowing whether certain types of entities exist without the benefit of philosophical reflection is defective.

An opponent of error theory might respond by claiming that this weaker implication is still unacceptable. On this line of response, we can know the answers to controversial ontological questions without engaging in any philosophical reflection. But this is implausible, since it is implausible that any source of knowledge could supply us with answers to these questions unaided by philosophical reflection. We suggest that there are exactly two fundamental sources of knowledge: thinking and perception. The information provided by all other sources of knowledge, such as memory or testimony, are ultimately drawn from perception or thinking. Controversial ontological doctrines cannot be established perceptually. Consider what ought to be the best case: visible concrete objects. It is tempting to think that we can establish whether there are tables simply by opening our eyes and looking! But even the ontology of tables is not so easy, since a table composed of indivisible particles looks just like a bunch of indivisible particles arranged in the same way but composing nothing (Merricks 2001, pp. 8-9.) Philosophical reflection is required to work out what we see. Nor can controversial ontological 
doctrines be established without sustained theorizing: if there are any good a priori arguments for any of these doctrines, careful philosophical work is required to formulate and assess them. We therefore hold that, without philosophical reflection, the prospects for discovering what exists are bleak.

To summarise: insofar as error theory conflicts with conservatism, error theorists may either reject conservatism, or they may argue, on a case by case basis, that the balance of evidence is against conservatism. The point is a general one. Given any putative source of evidence $S$ for a proposition $P$, an error theory about $P$ may either dispute whether $S$ is a source of evidence, or it may claim that $S$ 's evidential support for $P$ is defeated by the counter-evidence that the error theory marshals.

\section{Common sense}

Where error theory conflicts with some folk view - with some view commonly held by philosophers and non-philosophers alike - it is tempting to appeal to arguments familiar from discussions of scepticism. For instance, if faced with an error theory about the existence of some kind of common sense entities, such as minds or physical objects, some philosophers would take a leaf out of G.E. Moore's work (Moore 1959. Moore's anti-sceptical approach is endorsed by, for example, Armstrong (2006, p.160) and Pryor (2000, p.518).) Let $P$ be a common sense claim such that an error theory says that $P$ is untrue. The opponent of error theory then replies: I am more certain that $P$ is true than I am of the conjunction of the premises of any argument that the error theorist might use to argue against $P$. Thus Moore:

I cannot help answering: It seems to me more certain that I $d o$ know that this is a pencil and that you are conscious, than that any single one of these four assumptions is true, let alone all four (Moore 1959, p.143, his italics.)

But this Moorean reply faces a dilemma. If it is intended simply as a psychological claim ('I, the Moorean, am more confident that $p$ is true ...'), then it is unclear whether the Moorean claim has any probative force. It seems to be merely an autobiographical remark. Alternatively, if it is intended a normative claim ('I, the Moorean, am warranted to be more confident that $p$ is true . .'), then why should we accept the claim? Armstrong describes common sense claims as 'more certainly true than any evidence that is brought against them' (Armstrong 2006, p.160.) Yet if that is the case, it would presumably not be a brute fact. There would presumably be some reason why common sense claims have that pre-eminent status. The question, then, is what. The most obvious line of support for Moorean claims is given by considerations of conservatism. (See, for example, Lewis 1986, p.134) But that would be to fall back on considerations that we have already addressed and found lacking. In any case, 
it is not clear how conservatism could provide the degree of support required. The above quote from Armstrong takes common sense claims to be indefeasible; that no evidence can overturn them. Considerations of conservatism do not confer that degree of support on any claim. Furthermore, it is unclear what kind of considerations could do so, given that common sense claims do not admit of apodictic proof.

Some philosophers think that some things are epistemically superior to common sense, namely, science and mathematics. In the next section we consider whether respect for these disciplines rules out error theory.

\section{$10 \quad$ Naturalism}

Error theory and naturalism are somewhat similar theses: they are radical, iconoclastic theses that seek to undercut the pretensions of speculative metaphysics. But there is also a conservative element to naturalism, and it might be thought that this may bring naturalism into conflict with error theory.

Broadly speaking, naturalism claims that science is the best source of knowledge of the world. Naturalism about standards says that since science is the best source of knowledge of the world, scientific standards of evidence gathering and evaluation are the best standards. Naturalism about theories says that, for the same reason, scientific theories are the most informative theories and the most likely to be true. As Maudlin puts it (Maudlin 2007, p.1):

metaphysics, insofar as it is concerned with the natural world, can do no better than to reflect on physics. Physical theories provide us with the best handle we have on what there is, and the philosopher's proper task is the interpretation and elucidation of those theories.

How might naturalism conflict with error theory? Consider error theory about mathematics. This theory says that no mathematical sentence is (non-vacuously) true. It also says that there is good reason to believe the theory. This reason is as follows: If mathematics is about abstract entities (where an abstract entity is not located in space and time), then there is no explanation of how beliefs about such entities would be reliable (i.e. how such beliefs would be more likely to be true rather than untrue.) So our beliefs about such entities would not be reliable. Given this, we should believe that there are no abstract mathematical entities. It follows that we should believe that mathematical terms fail to refer, and so that no mathematical sentence is (non-vacuously) true (Field 1980; 1989.)

In response, John Burgess and Gideon Rosen appeal to naturalism about scientific standards. They claim that there is no philosophical argument powerful enough to override or overrule scientific standards of acceptability in the present instance (Burgess and Rosen 2005.) Now many mathematical 
sentences meet scientific standards of acceptability. Burgess and Rosen's naturalism entails that those mathematical sentences are acceptable. They conclude that error theory about mathematics is false.

We have three comments on this line of argument. First, the issue is more complicated than the straight clash envisaged by Burgess and Rosen between What Philosophy Says and What Science Says. Certainly, Field's argument for error theory about mathematics is a philosophical argument. But it crucially draws upon scientific considerations. In particular, the claim that there is no explanation of how we could have reliable beliefs about entities not located in space and time draws upon scientific considerations. Science gives explanations of the reliability of our beliefs about certain domains. In every case, the fact that the entities in the domains are located in space and time is an essential part of the explanans. By being so located, the entities can make a causal difference to their environment, and thereby to our cognitive states. Moreover, science offers no explanations of the (alleged) reliability of our beliefs about any domain whose entities are not located in space and time. So science provides evidence for, and no evidence against, the major premise of Field's argument. The significance of this point is that taking mathematical error theory to contravene naturalism is an over-simplification. The dispute between Field, on the one hand, and Burgess and Rosen, on the other, is not a dispute between those who take philosophy to be superior to science and those who do not. Each party extracts some consideration from science - against the reliability of mathematical beliefs, or for the acceptability of mathematical sentences - and develops a philosophical argument on this basis. The conflict is not between philosophical argument and science, but between two philosophical arguments each of which draws on science.

Our second comment seeks to show that Burgess and Rosen's argument is flawed. Let's grant to naturalism that no philosophical argument is powerful enough to override scientific standards of acceptability, and that much mathematical practice meets those standards. But what does meeting those standards involve? Presumably, in the case of mathematics, it involves showing that one's theorems are consequences of certain other mathematical sentences. It is then consistent for the error theorist to claim both that mathematical practice typically meets scientific standards, and that no mathematical sentences are (non-vacuously) true (see Liggins 2007.) Field takes just this view. He is both a mathematical error theorist and a revolutionary fictionalist about mathematics. Moreover, he not only allows that many mathematical sentences are acceptable by scientific standards, he also allows that there is a sense in which those sentences are true. This is the sense in which such sentences can be true-in-the-fiction-of-mathematics just as the sentences in Dickens' novel Oliver Twist are true-in-the-fiction-of-Oliver-Twist. (For more on this notion of truth-in-a-fiction, see Lewis 1983b.)

Our third comment is that this analogy with standard fictional works also explains why mathematical error theory is compatible with Burgess and Rosen's naturalism. Burgess and Rosen 
claim that scientific standards determine which mathematical sentences are acceptable and which are not, and that no philosophical argument is powerful enough to override scientific standards of acceptability in the present instance. The error theorist can take this to be a special case of the claim that which fictional sentences are acceptable and which ones are not is determined by standards internal to that fiction. For instance, why is the sentence 'Oliver Twist was an orphan' acceptable whereas 'Oliver Twist was a Martian' is not? The standards internal to Dickens's fiction determine the acceptability of the first sentence and the unacceptability of the second. As a first approximation, the standards say that a sentence $\mathrm{S}$ is acceptable by the lights of a fiction $\mathrm{F}$ if and only if $\mathrm{S}$ is included in $\mathrm{F}$, or is an obvious consequence of sentences included in F. (For discussion and some needed refinements, see again Lewis 1983b.) Moreover, no philosophical argument is powerful enough to overrule or override fictional standards of acceptability. If Dickens's fiction says that Twist was a bottle washer, then no philosophical argument (or non-philosophical argument for that matter) is sufficient to overturn what the fiction says. The standards internal to a fiction $\mathrm{F}$ are authoritative with respect to the acceptability of sentences in F. And the reason for this is simply that a sentence $\mathrm{S}$ is acceptable by the standards of $\mathrm{F}$ if and only if S-is-true-in-the-fiction-of-F.

To sum up: naturalism champions the primacy of scientific theory and standards over philosophical ones. Error theory would conflict with naturalism only where error theory conflicts with what science says. But identifying what science says is a further matter. As the quote taken from Maudlin earlier in this section indicates, scientific theories and standards need philosophical interpretation and elucidation. Our discussion of Burgess and Rosen's criticism of mathematical error theory illustrates how an error theory can repel a naturalistic attack without rejecting naturalism itself. Furthermore, science, and thereby naturalism, may themselves provide considerations in support of an error theory about a given discourse. ${ }^{4}$

\section{Conclusion}

We have shown that the prospects for error theory have been systematically underestimated. The road is now wide open for the further development of error theories across a wide range of discourses. The merits of error theories need to be settled on a case-by-case basis: there is no good general argument against error theories.

\footnotetext{
${ }^{4}$ Colour discourse is a case in point. The error theory about colour advanced by Hardin (1988) is philosophically controversial, but all parties appear to agree that the scientific basis that it draws upon is impressively rich and detailed.
} 


\section{References}

Armstrong, D.M. (2006) 'The Scope and Limits of Human Knowledge' Australasian Journal of Philosophy 84, pp.159-66.

Benacerraf, Paul. (1973) 'Mathematical Truth’ Journal of Philosophy 70, pp.661-79.

Boghossian, Paul and J. David Velleman (1989) 'Colour as a Secondary Quality’ Mind 98, pp. 81-103.

Brock, Stuart and Mares, Edwin (2007) Realism and Anti-Realism (Stocksfield: Acumen.)

Burgess, John and Gideon Rosen (2005) 'Nominalism Reconsidered' in Stewart Shapiro (ed.) Oxford Handbook of the Philosophy of Mathematics and Logic (Oxford: Oxford University Press): pp.515-535.

Christensen, David (1994) 'Conservatism in Epistemology’ Noûs 28, pp.69-89.

Davidson, Donald (1973-4) 'On The Very Idea of A Conceptual Scheme' Proceedings of the American Philosophical Association 47 pp.5-20.

DePaul, Michael R. (1998) 'Why Bother with Reflective Equilibrium?' In Michael R. DePaul and

William Ramsey (eds) Rethinking Intuition: The Psychology of Intuition and Its Role in Philosophical Inquiry (Lanham: Rowman \& Littlefield) pp.293-309.

Devlin, John (2003) 'An Argument for An Error Theory of Truth' Philosophical Perspectives, 17, Language and Philosophical Perspectives, 2003, pp.51-82.

Dummett, Michael (1978) 'Wittgenstein's Philosophy of Mathematics' in his Truth and Other Enigmas (London: Duckworth Press), pp.166-85.

Eklund, Matti (2007) 'Fictionalism' Stanford Encyclopedia of Philosophy http://www.seop.leeds.ac.uk/entries/fictionalism/

Evans, Gareth (1982) 'Can there Be Vague Objects?' Analysis 38, p.208.

Everett, Anthony (2005) ‘Against Fictional Realism’ Journal of Philosophy 102, pp.624-649.

Feigl, Herbert (1950) 'De Principiis Non Disputandum . . .? On the Meaning and the Limits of Justification' in Max Black (ed.) Philosophical Analysis (Ithaca, New York: Cornell University Press), pp.119-56.

Field, Hartry (1980) Science without Numbers: A Defence of Nominalism (Oxford: Basil Blackwell.)

Field, Hartry (1989) Realism, Mathematics and Modality (Oxford: Basil Blackwell.)

Grandy, Richard E. (1973) 'Reference, Meaning and Belief' The Journal of Philosophy 70, pp.439-52.

Hardin, C.L. (1988) Color for Philosophers (Indianapolis: Hackett Publishing Press.)

Harman, Gilbert (1986) Change of View (Cambridge, Massachusetts: MIT Press.)

Horwich, Paul. (1998) Truth (2nd ed.) (Oxford: Oxford University Press.) 
Horwich, Paul (2006a) 'A World without Isms: Life after Realism, Fictionalism, Non-Cognitivism, Relativism, Reductionism, Revisionism, and so on' in Patrick Greenough and Michael P. Lynch (eds.) Truth and Realism (Oxford: Oxford University Press), pp. 188-202.

Horwich, Paul (2006b) 'The Quest for REALITY' Dialectica 61, pp.5-16.

Hurley, S.L. (1989) Natural Reasons: Personality and Polity (Oxford: Oxford University Press.)

Jackson, Frank (1994) 'Realism, Truth and Truth Aptness' Philosophical Books 35. pp.162-9.

Jackson, Frank (1998) From Metaphysics to Ethics (Oxford: Clarendon Press.)

Johnston, Mark (1992a) 'Reasons and Reductionism’ Philosophical Review 101, pp.589-618.

Johnston, Mark (1992b) 'How To Speak of the Colors’ Philosophical Studies 68, pp.221-63.

Johnston, Mark (1993) 'Objectivity Reconfigured: Pragmatism without Verificationism' in John Haldane and Crispin Wright (eds.) Realism and Reason (Oxford: Oxford University Press), pp.85-130.

Jubien, Michael (1997) Contemporary Metaphysics: An Introduction (Oxford: Blackwell.)

Lepore, Ernie and Kirk Ludwig (2005) Donald Davidson: Meaning, Truth, Language and Reality (Oxford: Oxford University Press.)

Lewis, David (1983a) 'Radical Interpretation' (with Postscripts) in his Philosophical Papers volume 1 (Oxford: Oxford University Press), pp.108-21.

Lewis, David (1983b) 'Truth in Fiction' (with Postscripts) in his Philosophical Papers volume 1 (Oxford: Oxford University Press), pp.261-80.

Lewis, David (1986) On The Plurality of Worlds (Oxford: Basil Blackwell.)

Liggins, David (2006) 'Is there a Good Epistemological Argument Against Platonism?' Analysis 66, pp.135-41.

Liggins, David (2007) 'Anti-nominalism Reconsidered' Philosophical Quarterly 57, pp.104-111.

Loux, Michael (2002) Metaphysics: A Contemporary Introduction ( $2^{\text {nd }}$ ed.) (London: Routledge.)

McGinn, Colin (1977) 'Charity, Interpretation, and Belief' The Journal of Philosophy 74, pp.521-35.

Mackie, J.L. (1977) Ethics: Inventing Right and Wrong (London: Harmondsworth Press.)

Maudlin, Tim (2007) The Metaphysics within Physics (Oxford: Clarendon Press.)

Merricks, Trenton (2001) Objects and Persons (Oxford: Clarendon Press.)

Miller, Alexander (2002) 'Wright's Argument Against Error-Theories' Analysis 62, pp.98-103.

Moore, G.E. (1959) Philosophical Papers (London: George Allen and Unwin.)

Parfit, Derek (1984) Reasons and Persons (Oxford: Oxford University Press.)

Pryor, James (2000) 'The Skeptic and the Dogmatist' Noûs 34, pp.517-49.

Putnam, Hilary (1983) 'Convention: A Theme in Philosophy' Realism and Reason: Philosophical Papers, Volume 3 (Cambridge: Cambridge University Press), pp.170-83. 
Russell, Bertrand (1912) 'On the Notion of Cause' Proceedings of the Aristotelian Society 13, pp.1-26; reprinted in his 1918 Mysticism and Logic (London: Penguin.)

Russell, Bertrand (1914) 'The Relation of Sense-data to Physics' Scientia 16, pp.1-27; reprinted in his 1918 Mysticism and Logic (London: Penguin.)

Stanley, Jason (2001) 'Hermeneutic Fictionalism' in Peter A. French and Howard Wettstein (eds.) Midwest Studies in Philosophy, Volume XXV: Figurative Language (Oxford: Blackwell) pp. 36-71.

Tait, W.W. (1986) 'Truth and Proof: The Platonism of Mathematics' Synthese 69, pp.341-70.

Thagard, Paul and Richard E. Nisbett (1983) 'Rationality and Charity' Philosophy of Science 50, pp.250-267.

Vahid, Hamid (2001) 'Charity, Supervenience, and Skepticism’ Metaphilosophy 32, pp.308-325.

Vahid, Hamid (2004) 'Varieties of Epistemic Conservatism' Synthese 141, pp.97-122.

van Inwagen, Peter (1990) Material Beings (Ithaca: Cornell University Press.)

Wiggins, David (1980) 'What Would Be A Substantial Theory of Truth?' in Zak van Straaten (ed.) Philosophical Subjects: Essays in Honour of P.F. Strawson (Oxford: Oxford University Press.)

Williamson, Timothy (2007) The Philosophy of Philosophy (Oxford: Blackwell.)

Wright, Crispin (1992) Truth and Objectivity (Harvard: Harvard University Press.)

Wright, Crispin (1994) 'Response to Jackson’ Philosophical Books 35, pp.169-75. 